九州大学学術情報リポジトリ

Kyushu University Institutional Repository

\title{
A Study on the Mountain Village Income Increase Project : Focused on the Mountain Village Development Projects of Gyeonggi Province in Korea
}

Kang, Hag Mo

Gyeonggi-do Forest Environment Research Station

Kohroki, Katsuhisa

Laboratory of Forest Policy, Division of Forest Environment and Management Sciences,

Department of Forest and Forest Products Sciences, Faculty of Agriculture, Kyushu University

https://doi.org/10.5109/12874

出版情報: 九州大学大学院農学研究院紀要. 53 (2)，pp.563-568，2008-10-28. Faculty of Agriculture, Kyushu University

バージョン：

権利関係 : 


\title{
A Study on the Mountain Village Income Increase Project - Focused on the Mountain Village Development Projects of Gyeonggi Province in Korea -
}

\author{
Hag Mo KANG ${ }^{1 *}$ and Katsuhisa KOHROKI \\ Laboratory of Forest Policy, Division of Forest Environment and Management Sciences, \\ Department of Forest and Forest Products Sciences, Faculty of Agriculture, \\ Kyushu University, Fukuoka 812-8581, Japan \\ (Received June 12, 2008 and accepted July 16, 2008)
}

\begin{abstract}
Since the Mountain Village Development Projects (MVDPs) initiated in 1995 by the Korean government for the purpose of developing poor mountain villages, 138 mountain villages have been built as of 2006, and 450 more mountain villages are expected to be constructed during the period of the Mountain Village Promotion Plan Plan (2008 2017). However, MVDPs implemented so far have shown a variety of challenges such as inactive participation of local communities and failure of taking into consideration regional characteristics when promoting the projects. Therefore, this study examined basic production facilities and the operation, focusing on community leaders and residents in six mountain villages in Gyeonggi Province, Korea, where the MVDPs were complete. As a result, it was found that it is necessary to provide continuous technical guidance and financial assistance for the villages of which MVDPs had been completed, explore strategies to promote active participation of the leaders and sharpen their leadership, and select types of projects after thorough examination by regional experts on the basis of regional characteristics to induce active participation of residents in the basic production facilities.
\end{abstract}

\section{INTRODUCTION}

The population of mountain villages in Korea remains around $4 \%$, while mountain villages account for $47 \%$ of the country. Due to the geographical location, they are suffering poor social, cultural, and economic situations. In particular, lower productivity and absolute shortage of workforce have been worsening their economic situations. In addition, factors including workforce shortage with the growing aging trend, wage increase, and low position of forestry production have prevented forest from making a contribution to the household income increase in mountain villages. Nevertheless, mountain villages play a key role in making agricultural and forestry production, stable, achieving balanced development of the nation, and inheriting culture and tradition. Amid growing interest in environmental issues worldwide, supply of agricultural products and natural experience programs have been in progress by means of exchanges between those living in cities and mountain villagers to some degree, but absence of successors, workforce shortage, and uncertainty in the future of agricultural and forestry production by changing domestic and overseas conditions have been still getting in the way of mountain village activation. Therefore, the government initiated the Mountain Village Development Projects (MVDPs) in 1995 with the aim of developing poor mountain villages, and, as a result, 138 mountain villages have been built as of 2006, and 450 more mountain villages are expected to be constructed during the period of the Mountain Village Promotion Plan Plan (2008 2017) (Korea Forest Service, 2007a; Korea Forest Service, 2007b).

\footnotetext{
Gyeonggi-do Forest Environment Research Station, Osan, 447-290, Korea

* Corresponding author (E-mail: kanghagmo@hanmail.net)
}

Therefore, this study first looks into characteristics of mountain villages in Gyeonggi Province and examines developments of basic-production facilities and the operation in six mountain villages among 12 of which MVDPs have been complete by 2006 to find problems of the MVDPs and explore directions for the future.

\section{MATERIALS AND METHOD}

A questionnaire survey was administered for one month from early June to early July, 2007 on six mountain villages in Gyeonggi Province of which MVDPs had been complete: Gakhyeon-ri Jeokseong-myeon Paju City, (2001 2003), Jurok-ri Geumsa-myeon Yeoju-gun (2002 2004), Woibang-ri Sudong-myeon Namyangju City (2002 2004), Myeongdal-ri Seojong-myeon Yangpyung-gun (2002 2005), Naebang-ri Sudongmyeon Namyangju City (2003 2005), Eomso-ri Seorakmyeon Gapyeong-gun (2004 2006). The survey was conducted via face-to-face interviews with former and incumbent town heads and residents who participated in MVDPs, in regard to the operation of major public facilities in town, joint income-creating projects, scale and management method of public funds, operation of mountain village experience programs, and other opinions on MVDPs at large.

\section{RESULTS AND DISCUSSION}

\section{Overview of MVDPs}

The Korean government defines a mountain village as a village in remote and secluded places in mountains marginalized from social, economic, and cultural benefits and suffering poor industrial infrastructures with an excessively low population density, a high ratio of forest, low income, and badly developed living conditions. More 
specifically, while indices such as $70 \%$ or over forest ratio, $26 \%$ or below arable ratio, and 1.44 persons $/ \mathrm{km}^{2}$ population density were used to classify a region as a mountain village during the mountain village classification survey in 1996 , any region with $70 \%$ or over forest ratio against the area of eup/myeon administrative district, population density equal to or below the average of eup and myeon nation wide, and arable land ratio against the area of eup/myeon administrative district equal to or below the average of eup/myeon nationwide was classified as a mountain village, according to the Forest Basic Act enacted in 2001.

Mountain villages in Korea account for $47 \%$ $\left(46,181 \mathrm{~km}^{2}\right)$ of the country, with forests for $58 \%$ (3.74 million ha), arable land for 27\% (0.55 million ha), while the population ratio remains low at 4.6\% (1.94 million persons). Accordingly, for balanced development of the country, efficient use and management of forests, and income increase of poor households of mountain villages, the study conducted a basic mountain village survey on 119 cities and guns, 508 eups and myeons, and 4,973 administrative li nationwide, in order to provide basic data for the efficient implementation of mountain village promotion policies and establishment of basic plan, in accordance with the Forestry and Mountain Villages Promotion Law (revised and issued on Dec. $31^{\text {st }}, 2001$ ).

As far as the MVDPs implemented so far were concerned, 138 villages were established from 1995 to 2006 , with 66 villages under construction or design as of 2007 . The MVDPs were classified into four types such as a vacation-linked mountain village, forest-income creating mountain village, farming-forestry combined mountain village, comprehensive development mountain village, in consideration of regional characteristics, and funds for the MVDPs were invested largely in three areas such as construction of basic production facilities (forest products, mountain village industrial infrastructure construction, etc.), improvement of living conditions (construction of community base, culture and welfare facilities, environment purification facilities, etc.), and development of income sources (individual income creating projects using forests and mountains and vacation facili- ties). The total investment from 1995 to 2006 amounted to 1.985 trillion won, consisting of 1.324 trillion won of national fund, 51.7 billion won of regional fund, and 14.4 billion won of loan. Meanwhile, it is planned to invest 6.873 trillion won in 450 villages focusing on six key tasks such as increase of the value of mountain village as forest resources, construction of industrial base for mountain villages, improvement of living conditions, promotion of mountain village experience tours, training of workforce in mountain villages, and reorganization of mountain village support programs during the Mountain Village Promotion Plan (2008 2017) (Table 1). Meanwhile, the Korean government evaluated that the MVDPs had achieved so far income increase, population growth, improvement of living conditions, and laying an institutional foundation for the stable implementation of the MVDPs, while pointing out lack of natural resources exploration and directions for long-term development, absence of strategies, lack of basic plan and implementation design, insufficient specialty agricultural products, income sources by village and branding, government-led top-down MVDPs, and poor evaluation, follow-ups, and support of MVDPs as challenges for the future. Besides, researchers added more challenges such as increase of mountain village promotion funds, promotion of active participation of communities, implementation of the projects fit to characteristics of mountain villages, wider use of forest products for income increase, and expansion of positive forest management and maintenance strategies. (Kwak and Kim, 2002; Kim, 2002; Korea Forest Service, 2003a; Shon and Chang, 2002; Kang et al., 2005; Korea Forest Service, 2007a; Korea Forest Service, 2007b; Kim et al., 2004).

\section{Overview of basic production facilities in moun- tain villages in Gyeonggi Province}

The MVDPs in the region began with Seoksan-ri Danwal-myeon Yangpyeong-gun in 1996, and 19 villages are expected to be built by 2009, with a total of 21.339 billion won of funds to be invested (Gyeonggi province, 2007). However, construction of basic production facilities among others should take into consideration village-

Table 1. Summary of mountain villages by year

\begin{tabular}{|c|c|c|c|c|c|c|c|c|}
\hline \multirow[b]{2}{*}{ Division } & \multirow{2}{*}{$\begin{array}{c}\text { Completed } \\
(1995 \sim 2006)\end{array}$} & \multicolumn{5}{|c|}{ Those in progress in 2007} & \multicolumn{2}{|c|}{ Mountain Village Promotion Plan (for 10 yrs) } \\
\hline & & Total & $1^{\mathrm{st}}$ & $2^{\text {nd }}$ & Planned & Total & $\begin{array}{c}1^{\text {st }} \text { half } \\
(2008 \sim 2012)\end{array}$ & $\begin{array}{c}2^{\text {nd }} \text { half } \\
(2012 \sim 2017)\end{array}$ \\
\hline Total & 138 & 66 & 18 & 15 & 33 & 450 & 150 & 300 \\
\hline Gyeonggi & 12 & 7 & 2 & 5 & - & - & - & - \\
\hline Gangwon & 29 & 13 & 3 & 3 & 7 & - & - & - \\
\hline Choongbuk & 13 & 6 & 2 & - & 4 & - & - & - \\
\hline Choongnam & 18 & 6 & 2 & - & 4 & - & - & - \\
\hline Jeonbuk & 21 & 13 & 3 & 3 & 7 & - & - & - \\
\hline Jeonnam & 14 & 6 & 2 & 2 & 2 & - & - & - \\
\hline Gyeonbuk & 18 & 11 & 3 & 2 & 6 & - & - & - \\
\hline Gyeonnam & 13 & 4 & 1 & - & 3 & - & - & - \\
\hline
\end{tabular}

Sources: 1) Korea Forest Service. 2007 Plan for the Mountain Eco-Villages Construction Project.

2) Korea Forest Service. 2007 Mountain Village Promotion Plan. 
specific characteristics fully, and some pointed out that residents were not responded favorably to financing projects in terms of interest rates and payback periods, with no remarkable outcome (Kang et al., 2005) (Table 2 ). Present situations of the construction of basic production facilities in the six mountain villages are as follows:

\section{Major facilities}

First of all, in the case of Gakhyeon-ri Jeokseongmyeon Paju City, major production facilities included $19,800 \mathrm{~m}^{2}$ of wild grape cultivating facilities, 16 mushroom plantation facilities, five mountain herbs plantation facilities, three mountain cottages, one service and special sales area, and one campsite, while the plantation and production of wild grapes, mushrooms, and mountain herbs were based on a private management by around five residents, not joint management by the com- munity. This was because of restrictions on the lease and possession of the land for facilities installation, smallscale plantation, and failure of participation due to personal situations. In the case of facilities such as mountain cottages, special sales area, and campsites, since there were a small number of visitors, and sales of agricultural products were sluggish, four to five residents managed the facilities jointly and provided part of profits for public funds for the community. Major facilities for Jurok-ri Geumsa-myeon Yeoju-gun included 12 ha income-production complex, seven mountain herbs plantation facilities, 26 mushroom plantation facilities, one green vacation facility, and five mountain cottages, and mountain herbs and mushrooms plantation were managed privately by seven to eight residents, unlike the original plan of joint plantation. In the income-production facilities, ogalpi, todok, and broad bellflowers were

Table 2. Overview of basic production facilities constructed under the MVDPs

(unit: million won)

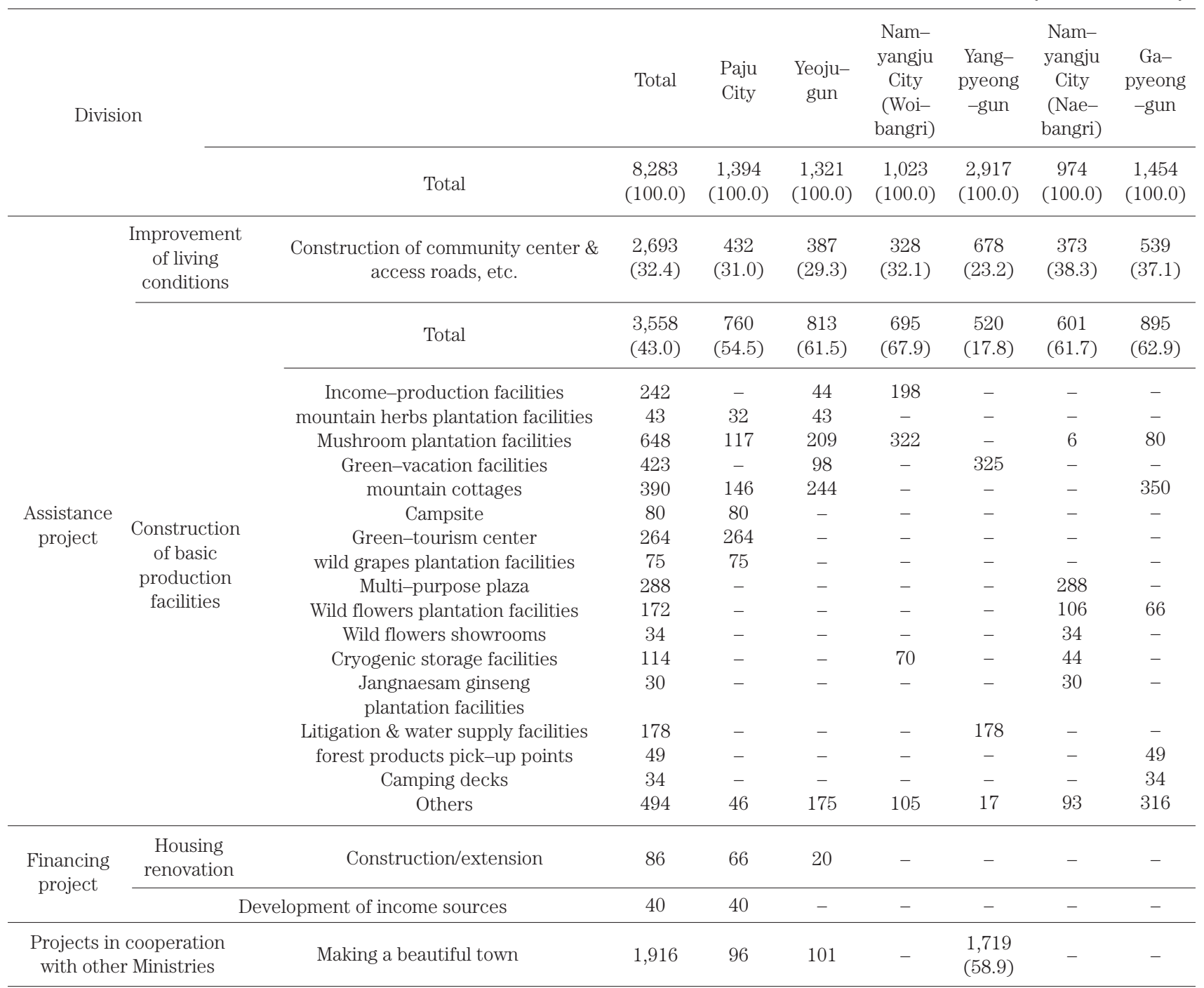

Notes: 1) Figures in parenthesis are the ratio (\%) of the total.

2) The improvement of living conditions projects refer to resting places for the aged and healthcare centers, renovation of deserted schools, tube wells, pavement/extension of access roads, forest culture centers, plazas, information signs for villages, waster water treatment facilities, and mountain-climbing paths and forest therapy facilities, public warehouses, Internet connections, and driers for agricultural products are also included in the basic production facilities construction project.

Source: Gyeonggi Province. 2007 Internal Data. Plan and Results of MVDPs. 
planted in the $16,500 \mathrm{~m}^{2}$ government-owned land in 2004, but for some reasons including poor management, about 40\% remained currently, which was planned to be used as a mountain village experience facility in the future. Mountain cottages and green-vacation facilities provided visitors with accommodation and meals in summer and earned 12 million won as gross income in 2006, while residents worked for the facilities and were paid. However, the survey showed that management and maintenance was difficult because most of the profits were spent on the maintenance of the facilities. Major facilities in Woibang-ri Sudong-myeon Namyangju City included income-production facilities of $6,600 \mathrm{~m}^{2}$ and five mushroom plantation facilities. In the case of income production facilities, private forest was leased for free in which dreup and todok were planted in 2004. In 2006, gross income amounted to 3 million won and 5 million won, respectively. In the mushroom plantation facilities, pyogo mushroom and saesongee mushroom were planted, with the outcome of 30 million won and 150 million won of gross income, as a result of joint work of the village as a whole. Major facilities of Myeongdal-ri Seojong-myeon Yangpyung-gun included five greenvacation facilities, production facilities of 7 ha. The green-vacation facilities opened in July 2006, earning 15 million won of gross income for six months, and it was planned to grant 3\% of gross income as a public fund from 2007. In 2004, Jangnaesam ginseng was planted in the production facilities in leased government-owned forests, which have not been harvested, but the area was planned to be expanded further. Major facilities of Naebang-ri Sudong-myeon Namyangju City included $1,181 \mathrm{~m}^{2}$ of wild flowers plantation facilities, $280 \mathrm{~m}^{2}$ of mushrooms plantation facilities and $66,000 \mathrm{~m}^{2}$ of production facilities at the expense of residents. The wild flowers plantation facilities have generated no income yet, and mushroom plantation facilities produced 4 million won of gross income in 2005, while resulting in no income in 2006 due to litigation problem. In the production facilities, dreup, chinamul, todok, and broad bellflowers were planted- with the gross income of 0.7 million won and 0.3 million won from dreup and chinamulin 2006, respectively. Major facilities of Eomso-ri Seorak-myeon Gapyeong-gun included five mountain cottages and ten mushrooms plantation facilities. Mountain cottages were built in 2006 and expected to produce 7 million won of gross income in 2007, along with 2.5 million won of gross income from comprehensive facilities housing volleyball court, public cooking facilities, and shower booths. Mushroom plantation facilities were run privately by three residents.

Public funds and mountain village experience programs

In the case of Gakhyeon-ri Jeokseong-myeon Paju City, there was 25 million won as of 2007 of which 5 million won was come from the MVDPs, and it appeared hard in the near future to increase the funds by the facilities built by the MVDPs including mountain cottages. In addition, despite the unsatisfactory level of the outcome of the experience programs in 2006, largely with the help of promotion efforts via the Internet covering Information Network Villages and MVDPs, visitors to the wild grapes plantation facilities increased gradually, and 20 farm households of wild grape plantation were participating in the experience programs, with 11 households designated as an experience farm house, with the assistance of the National Agricultural Cooperative Federation (NACF) in facilities and promotion. In the case of Jurok-ri Geumsa-myeon Yeoju-gun, as of 20071.8 million won of public funds were raised most of which, however, were raised through community sponsorship, and income from mountain cottages and others were predicted to decrease gradually, as most of them were spent to pay for operating costs covering electricity, fuel, and labor. Experience activities were led by one resident in 2006, not jointly managed, and participants totaled 10,000 at a fee of 12,000 won per person for participation. Activities under the programs included picking sweet potatoes, making ingeolmi, dyeing mud yell, and picking strawberries and melons. To meet the need for workforce, residents of the village worked with payment. As of 2007, three to four farm households were found to want to participate in green rural village experience programs. In the case of Woibang-ri Sudong-myeon Namyangju City, a jointly owned dry field was sold to raise 60 million won of public fund, with additional 10 million won of funds raised from the MVDPs. In 2007, it was expected to earn 15 million won of net income from joint income-making project. Meanwhile, under a joint project, a total of 80 persons participated in an experience program in 2006, and 400,000 won out of the profit was used to raise the public fund. In 2006, residents were unwilling to participate in the experience activities, due to poor profitability, despite growing demands, but in 2007 they intended to increase valley experience activities. Myeongdal-ri Seojong-myeon Yangpyung-gun owned 30 million won currently, most of which were from community sponsorship raised via sporting events of the village and gratitude for funeral service. The experience activities were operated not by residents, but by an organization named "Forest of Life", with $10 \%$ of income being given to the village. Naebangri Sudong-myeon Namyangju City had 7 million won of public fund currently among which 5 million won was, however, from community sponsorship and 2 million won from joint collection of Acer mono tree extracts. Although experience programs were not provided due to the lack of places and facilities and the lower level of profit margin, it was planned to offer wild flowers-based experience activities in 2007. Eomso-ri Seorak-myeon Gapyeong-gun also had 40 million won of public fund, it was found to be raised from other sources than the MVDPs. The experience activities were planned to cover $1,000 \sim 1,500$ people in 2007 , but it was found that the lack of facilities such as accommodation and cooking areas made it hard to house more people.

Achievements and Problems of MVDPs

In the case of Gakhyeon-ri Jeokseong-myeon Paju City, although the economy was sluggish due to the absolute shortage of farmland, it was expected that increase 
of visitors would result in the rise of demands for guesthouses and restaurants and thereby increase of profit. Moreover, wild grape farming households saw the fact that the increasing sales through experience activities and on-site purchase by and the increase of land price as a good outcomes of the MVDPs, while pointing out side effects such as increased waste and water pollution in and around the village by the increase of visitors. Resdients of Jurok-ri Geumsa-myeon Yeoju-gun said that MVDPs made a contribution to provision of financial support for green house facilities expenses, increase of guesthouses and land prices, while raising problems such as increasing land possession by outsiders, and decreasing arable lands due to the construction of rural houses and resort villas. In particular, many of the participants emphasized that it would be necessary to listen to objective opinions of experts in advance, rather than rely on that of a majority of the residents to make MVDPs successful and conduct a validity test at the time of construction of individual facilties. In the case of Woibangri Sudong-myeon Namyangju City, participants said that the MVDPs played a role in increasing sales of specialpurpose produces such as pyogo mushroom, dreup, and todok and land prices, and enhancing resident's attitudes, pointing out the absence of consistent support as a problem. In the case of Myeongdal-ri Seojong-myeon Yangpyung-gun, participants said that the MVDPs contributed to smooth permit-granting process for water supply and sewage system installation and construction, improved water quality, and increase of land prices, while many of them insisted on reduction of lease on government-owned forests needed for short-come incomecreating crops or lease for free and more support for income-creating crops than for infrastructures. In the case of Naebang-ri Sudong-myeon Namyangju City, participants saw enhanced ties among residents and discussion culture, land price increase, and rising sales of agricultural products via the Internet as good outcomes, while MVDPsin the future should take into consideration village-specific characteristics and landscape. In the case of Eomso-ri Seorak-myeon Gapyeong-gun, participants mentioned land price increase, improved living environment and rising sales of agricultural products via the Internet as good outcomes, pointing out a relatively small number of facilities insufficient to meet various needs covering experience activities.

\section{CONCLUSION}

1. Major basic production facilities in the six mountain villages were found to be mushroom plantation facilities, green-vacation facilities, and mountain cottages among which mushroom plantation facilities were the highest in number, built in five villages. In the case of Woibang-ri Sudong-myeon Namyangju City, while mushroom plantation facilities were operated jointly by residents, some residents were found to use them independently in the remaining four villages.

2. As for green-vacation facilities and mountain cottages, they served to become an income source as an accom- modation in summer, but did not make a contribution to the increase of income due to small scale and management costs.

3. It was found that dreup, todok, and broad bellflowers were planted in forests in income-production facilities, and Woibang-ri Sudong-myeon Namyangju City earned 8 million won of gross income from dreup and todok in 2006, while other villages gained no income due to poor management and short-term period of plantation.

4. The total of public funds of the six mountain villages amounted to 180 million won and average per village was 30 million won. However, these public funds were raised mostly from community sponsorship than the MVDPs.

5. Five villages in the six were found to participate in the mountain village experience program, but the program failed to be activated due to lack of facilities, low profit margin, and inactive participation of the community at large. Nevertheless, as the program was evaluated to have a strongly positive effect on income increase via the increase of sales of agricultural produces, most of the villages were found to plan its expansion.

Discussions so far have resulted in the following challenges:

1. It is necessary to put in place programs to help gain income in short term by means of increasing lease of government-owned or publicly owned lands and reduction of rental fees, and it is considered necessary to continue technical guidance and financial support even for the mountain villages of which MVDPs were complete so as to ensure the original goals will be achieved.

2. In order to increase income using various buildings and basic production facilities built as a result of the MVDPs, joint effort among residents is essential, and in order to promote active participation and strong leadership of leaders, training and support programs for leaders are considered important.

3. Despite its ultimate goals of MVDPs, that is, balanced development of the country through forest management and improvement of timber production and functions for public good, all of the six mountain villages were found to have no plan for forest management and maintenance. Therefore, strategies for management and maintenance of local forests should be included in the MVDPs.

4. Even though inactive participation of mountain villagers was mainly because of differing e-production structures by household such as land ownership, employment structure, and composition of family workforce, the one favored by a majority of residents was chosen without in-depth analysis of experts and consideration of regional characteristics, and therefore, the structures should be fully considered at the time of selecting the type of the project in the future.

5. Finally, most of the mountain villages of which MVDPs were complete was found to make no contribution to 
the increase of household income, due to shorter operation period of basic production facilities and less experience, while specialty produces have been enjoying increased sales via various promotion efforts with resort to the Internet and others. In addition, since the increasing mountain village experience programs and participation of those living in cities have served to provide a good opportunity to change attitudes toward forests and nature of people and promote the importance of mountain villages, it is imperative to implement more fulfilling MVDPs continuously.

\section{REFERENCES}

Gyeonggi province. 2003a Overview of the MVDPs in Gyeonggi province

Gyeonggi province. 2003b Plan for 2003 MVDPs in 2003

Gyeonggi province. 2004 Plan and Results of Mountain Village Development Projects

Gyeonggi province. 2003c Report on the National Basic Survey on Mountain Villages

Gyeonggi province. 2007 Assistance for Mountain Villages

Kang, H. M., Choi. S. I., Kim. J. S., Jeong. I. S., Oh. S. W., Lee. S. H and N. Sato. 2005 A Study on the Development Project of Mountain Settlements in Korea. J. Fac. Agr. Kyushu Univ.,
50(1): 295-311

Kim, E. K. 2002 Changes and Direction of Mountain Village Development in Korea. Korean Journal of Forest Economics, 10(2): 95-105

Kim, E. G., Kim. D. H and B. I. Yoo. 2004 The Correlation Analysis Between Forest Resources and Specific Characteristics of Mountain Villages in Gyenongsangnam-do. Korean Journal of Forest Economics, 12(1): 70-83

Korea Forest Service. 2003a Annual Report on Forest and Forestry Trends for 2003

Korea Forest Service. 2003b Materials for Education of National Basic Survey on Mountain Villages

Korea Forest Service. 2004 Detailed Plan for Major Projects in 2004

Gyeonggi province. 2007 Plan for Mountain Village Development Projects and the Results

Korea Forest Service. 2007a Plan for the Mountain Eco-Villages Construction Project

Korea Forest Service. 2007b Basic Mountain Village Promotion Plan

Kwak, K. H and S. B. Kim. 2002 Management Status and Development Direction of Case Areas in Mountain Village Package Development. Korean Journal of Forest Economics, 10(2): $117-124$

Shon, C. H and W. W. Chang. 2002 A Status and Improvement Direction of Case Areas. Korean Journal of Forest Economics, 10(2): 106-116 